\title{
Experimental research of reaction blading on air turbine VT-400
}

\author{
Marek Klimko ${ }^{1, a}$, Daniel Okresa ${ }^{1}$ \\ ${ }^{1}$ University of West Bohemia, Department of Power System Engineering, Univerzitní 8, 30614 Pilsen, Czech Republic
}

\begin{abstract}
The article deals with testing a reaction blading on an experimental air turbine VT-400, which is situated at the Department of Power System Engineering at University of West Bohemia. Experiments were carried out in cooperation with an industrial partner Doosan Skoda Power. The outputs of these measurements are for example: results of the stage efficiency depending on the speed ratio $\mathrm{u} / \mathrm{c}$, the course of reaction, the input and output angles and profile losses along a blade.
\end{abstract}

\section{Introduction}

One of the important steps when designing a flow section of a steam turbine is to calculate efficiency, or more precisely, its preliminary estimation (efficiency prediction). This is a valuable and confidential know-how of every steam turbine producer. It is a long-term process carried out in research laboratories, including experience from real operation. Increasing speed and improving quality of CFD calculations enables to simulate the influence of a whole range of geometrical and operational factors, yet experimental testing still maintains its important role.

This paper represents a continuation of a long-term research carried out at the Department of Power System Engineering (KKE) in a close cooperation with the company DOOSAN ŠKODA POWER (DSPW). In the past, the research on an experimental air turbine was focused on secondary losses caused by flow in the stage of a steam turbine, as a result of 3Dflow in the channel endwall areas. The objective of the studies was to find a suitable solution, which would lead to the most significant decrease of those losses by a 3Dblade shaping method.

A simple construction layout of the test rig enables an effortless exchange of stator and rotor wheels according to measurement requirements. An input channel layout is possible to be changed as well. A large advantage of the experimental air turbine VT 400 is its easy and fast launch, and primarily its cheap operation, in comparison with a steam turbine. However, the use of this turbine is limited in some extent by the operational parameters range, especially by Mach and Reynolds numbers.

Two variants of reaction stages have been tested at the Department during the past two years. There are two types of stator (high aspect ratio blading: "Pretlak-1" and low aspect ratio blading: "Pretlak-2"), whereas the rotor part of the stage remains the same for both variants.
There are basic geometric characteristics for both tested variants mentioned in the article, including a description of the measuring methods and evaluation of measured data, followed by results of graphic behaviour of selected parameters. Tested variants are compared from the point of view of the stage efficiency, reaction, Mach and Reynolds numbers, and also regarding the aspect of profile losses.

\section{Basic description of the experimental air turbine VT-400}

It is a single-stage air turbine located in the compressor suction. The turbine is a model of a high-pressure steam turbine component stage in the scale of 1:2. Apart from almost constant air inlet parameters, this layout also provides an easy access to the turbine and measuring points.

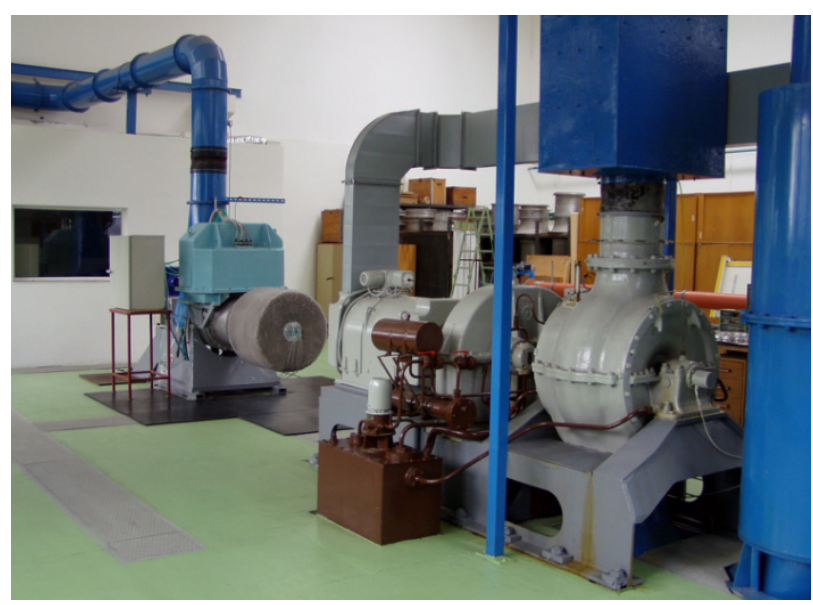

Figure 1. Experimental device.

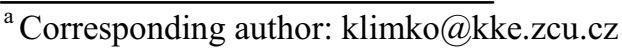


A part of the test rig is a direct-current dynamometer, which serves for the determination of speed and torque. Air, volume of which is measured by a nozzle, leaves the blower pressure discharge and out of the laboratory.

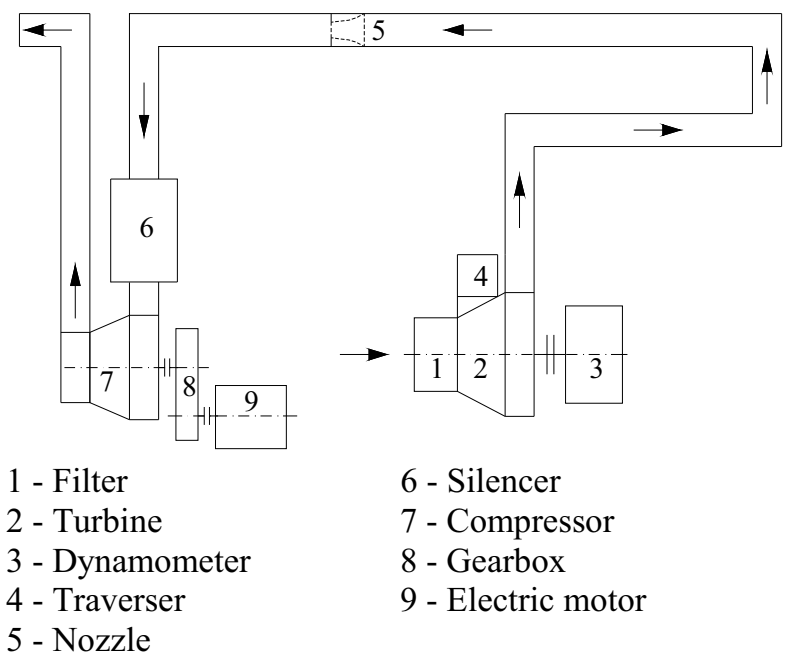

Figure 2. Scheme of the device.

The turbine is equipped by a traverser device. The traverser enables the probe to move radially (under the blade root section and above the blade tip), peripherally (across two stationary blade spacings), and it also allows its automatic turning in the flow direction. That enables a thorough measurement of a flow field behind stator and rotor blades.

There are several static pressure extractions on the turbine - in front of the stage, inside, and behind it, always on the root section and tip diameter. There are holes at the input, for inserting e.g. Prandtl probe and measuring the inlet flow. All pressures are scanned by a fast, 16-channel pressure transducer. Temperatures are scanned by a resistance thermometer in front of and behind the stage. The probe measurement and move is automatic; the utility program is created in LabView 7.

\section{Tested variants of reaction blading}

In 2013 DSPW proposed two versions of a stage designed for testing on the ZCU air turbine, in accordance with newly prepared methodologies and using new profiles for reaction blading. The aim is to verify design data concerning aerodynamics, and to obtain data for specification of a loss model of reaction stages. The variants differ in aspect ratio of a stationary blade - the main parameter influencing secondary losses development. The basic geometrical data are summarized in Tab. 1. The blading has been produced and tested on the air turbine VT-400.

\section{Principle of the measurement course and basic procedure of data evaluation}

Basically, there are 2 elementary types of measuring on the air turbine:

1) Turbine integral characteristics
The turbine is equipped with a set of static pressure extractions, which determines the pressure drop on the stage (pressures in front of and behind the stage) and also the stage reaction at the root section and the tip (according to the pressure extractions behind stator). The turbine is connected to a dynamometer, which provides directly measured values of speed and the moment of torsion. The third, and significant, value is a flow rate, which is detected by a precise nozzle in the pipeline between the turbine and the blower.

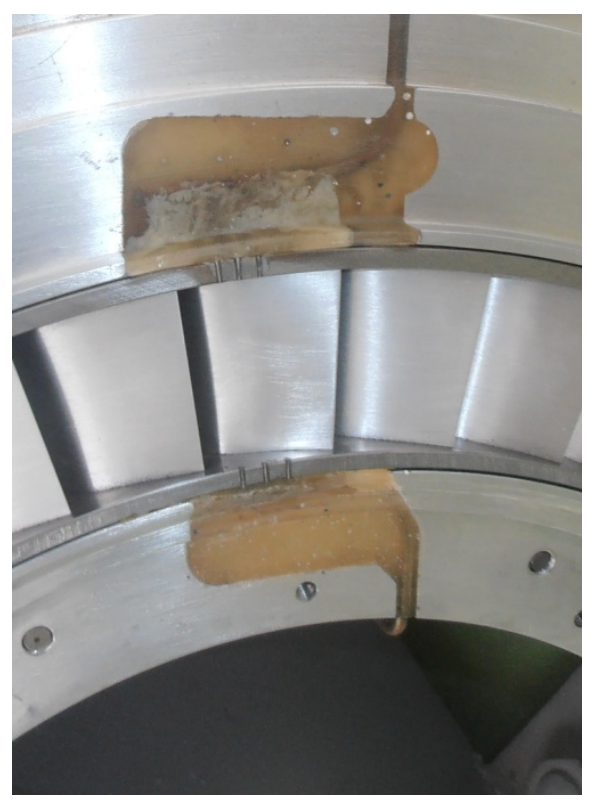

Figure 3. Locations of static pressure extractions on the nozzle.

\section{2) Traversing of flow fields}

By a pneumatic (5-hole) probe, which is fixed in the traversing device, velocity and pressure fields behind stator, and also behind rotor when relocated, can be examined in detail. These measurements do not directly provide the final data, but data determined for further proceeding - averaging, recalculating important points of the expanse line etc. The final output is, for instance, distribution of losses, angles, reaction etc. along the blade length.

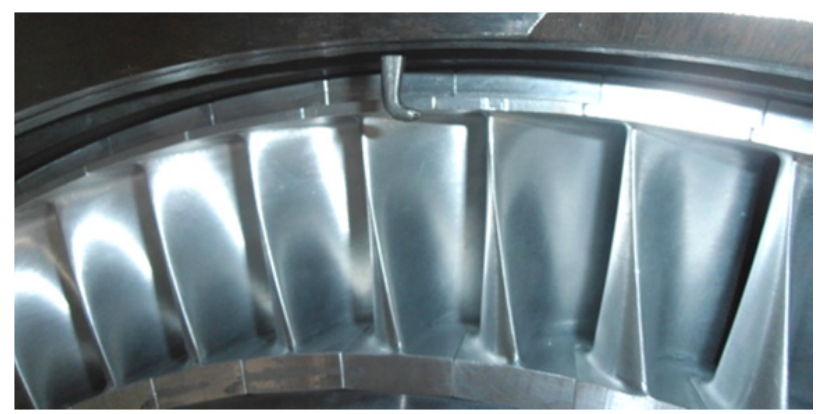

Figure 4. Detail of a 5-hole probe. 
Table 1. Basic geometrical characteristics of both variants.

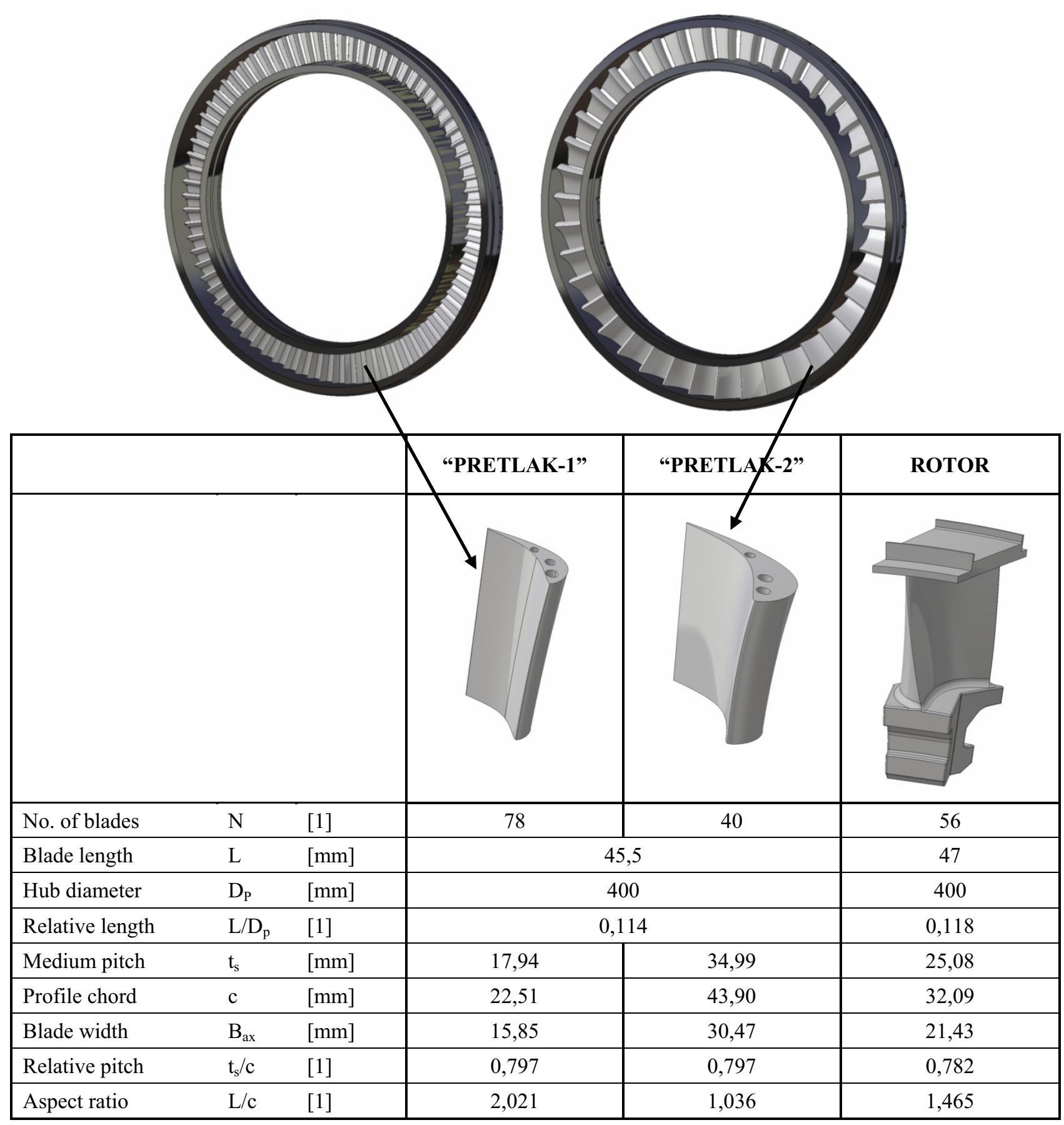

\subsection{Turbine integral characteristics}

The inlet pressure in front of the turbine is determined by atmospheric pressure, with the respect to the experimental device layout (an open suction tunnel), and only outlet pressure, and thus the pressure drop on the stage can be changed. The pressure drop is changed by the blower performance, or more precisely, by the performance of the powering engine. Changes are carried out in steps and manually, which makes concrete required mode settings complicated by maintaining a constant state.
Changing the pressure ratio at fixed turbine speed enables to change the velocity rate $\mathrm{u} / \mathrm{c}$ and obtain the stage basic integral characteristics - dependence of efficiency on the $\mathrm{u} / \mathrm{c}$ ratio. This characteristic can be measured for various turbine speed.

Basic integral data can be evaluated from each measuring point:

- barometric pressure and temperature (measured directly) + density recalculation,

- moment of torsion and speed (measured directly) + bearing and friction losses recalculation (dissipation),

- static pressure in front of and behind the stage (measured directly) + density recalculation, 
- flow rate (recalculation from pressures on the nozzle and behind the stage temperature),

- reaction on the root section and the tip (recalculation from pressures behind stator, varied definitions),

- inlet and outlet velocity (recalculation from annular areas in front of and behind the stage, flow rate and other data),

- stage efficiency (recalculation according to varied definition (total-static, total-total),

- velocity ratio $\mathrm{u} / \mathrm{c}$ (recalculation according to varied definition (total-static, total-total),

- another stage pure characteristic numbers (Mach and Reynolds numbers).

As mentioned above, we are able to change the velocity ratio $\mathrm{u} / \mathrm{c}$ by changing the pressure ratio at fixed turbine speed, which results in one of the most essential stage characteristics - efficiency dependence on the $\mathrm{u} / \mathrm{c}$ ratio. The turbine speed values have been set to 2000 , 2300, 2700, 3000 and 3400 RPM during measuring both variants, which changed the pressure drop, Mach number, and partially Reynolds number as well. We have agreed with DSPW to focus on speed of $2300 \mathrm{rpm}$. The objective of the measurement was to obtain the turbine optimum operating point, i.e. such a point where the turbine reaches the highest efficiency value with the corresponding optimum velocity ratio u/c (Fig. 5).

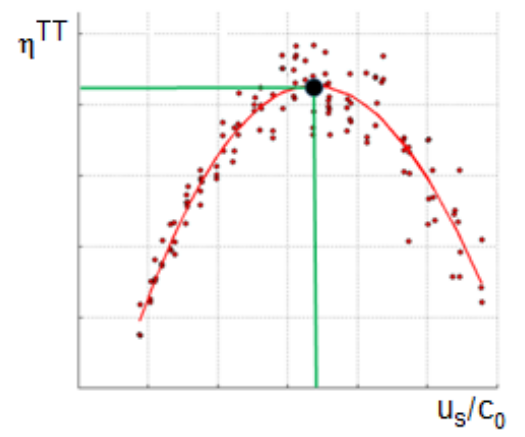

Figure 5. Determination of the turbine optimum operating mode

This optimum operating point was our input when executing stationary measurements of pressure fields behind stator and rotor.

\subsection{Traversing flow fields}

This measurement provides very important information about flow in the stage. It leads to a stationary pressure, or rather a velocity image of the flow field, and after suitable peripheral data averaging also a behaviour of quantities along the blade length, which is highly valued by designers. It is not only about loss values, but also velocities, or more precisely, angles for calculating of flow incidences and deviations; furthermore, and for instance, the reaction level or volumetric flow etc. Such data provides, when compared with the theoretical design, substantial information on behaviour and functioning of shape modifications of blades, or the influence of off-design modes.
Flow fields measurement takes place at a selected operating mode; in our case it was the turbine optimum operating duty, which was set on the basis of the pressure drop and the $\mathrm{u} / \mathrm{c}$ ratio. This operating mode is maintained, as good as it can be, on a constant value in the tunnel. Measuring is performed by a 5-hole pneumatic probe of the size of $4 \mathrm{~mm}$, which represents approximately $9 \%$ of the blade height, and thus the acquired data may be partially distorted. Due to the probe size, including its holder, an axial gap between stator and rotor was enlarged. The probe is fixed in the traversing device. It can be moved manually in two positions - for measuring behind stator or rotor. The traverser enables a peripheral probe shift (approximately $22^{\circ}$ ), radial shift (under the root section and above the tip), and also its flow-wise turn (automatically according to the comparison of pressures from the left and right probe extraction).

\subsubsection{Traversing behind stator}

Measuring is relatively accurate and its evaluation fairly simple. Isentropic expansion (velocity) can be determined from integral static pressure and static pressure from the probe, and, for example, losses in the stationary blades cascade can be calculated from the total pressures. Furthermore, an outlet angle from stator or stage reaction can be analyzed as well. An inlet flow angle into rotor or corresponding components of relative velocity can be analyzed by further recalculation (by including the peripheral velocity).

This can be implemented on the whole measured flow field (constant total pressure is considered in front of the stage), or more often the measured data are averaged after individual radials and one representative value is defined for a particular radial.

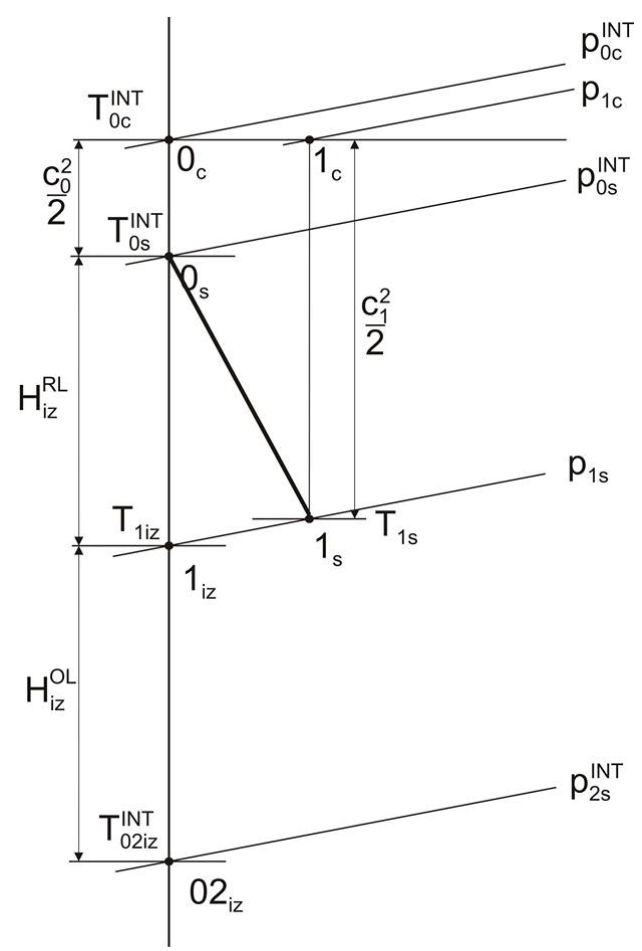

Figure 6. T-s diagram of expansion on stator 
Stage reactions (static-static, total-static) are defined generally:

$$
\begin{gathered}
\rho^{S S}=\frac{H_{i z}^{O L}}{H_{i z}^{S T}} \\
\rho^{T S}=\frac{H_{i z}^{O L}}{H_{i z}^{S T}+\frac{c_{0}^{2}}{2}}
\end{gathered}
$$

We are able to calculate isentropic drops $H_{i z}^{S T}, H_{i z}^{O L}$ and $H_{i z}^{R L}$ based on the difference of temperatures and isobaric specific heat capacity.

$$
\begin{gathered}
H_{i z}^{S T}=c_{p} \cdot\left(T_{0 s}^{I N T}-T_{02, i z}^{I N T}\right) \\
H_{i z}^{O L}=c_{p} \cdot\left(T_{1, i z}-T_{02, i z}^{I N T}\right)=H_{i z}^{S T}-H_{i z}^{R L} \\
H_{i z}^{R L}=c_{p} \cdot\left(T_{0 s}^{I N T}-T_{1 i z}\right)
\end{gathered}
$$

Temperature $T_{0 s}^{I N T}$ is measured directly, temperatures $T_{02, i z}^{I N T}$ and $T_{1 i z}$ are calculated as follows:

$$
\begin{aligned}
& T_{02 i z}^{I N T}=T_{0 s}^{I N T} \cdot\left(\frac{p_{2 s}^{I N T}}{p_{0 s}^{I N T}}\right)^{\frac{\kappa-1}{\kappa}} \\
& T_{1 i z}=T_{0 s}^{I N T} \cdot\left(\frac{p_{1 s}}{p_{O s}^{I N T}}\right)^{\frac{\kappa-1}{\kappa}}
\end{aligned}
$$

Pressures $p_{O S}^{I N T}$ and $p_{2 s}^{I N T}$ are measured by extractions of static pressures in front of stator and behind rotor, and pressure $\mathrm{p}_{1 \mathrm{~s}}$ is acquired from data from the 5-hole probe after recalculation according to calibration. We obtain from the velocity triangle:

$$
\begin{gathered}
T_{1 s}=T_{0 C}^{I N T} \cdot\left(\frac{p_{1 s}}{P_{1 c}}\right)^{\frac{\kappa-1}{\kappa}} \\
T_{0 c}^{I N T}=T_{0 s}^{I N T}+\frac{\mathrm{c}_{0}^{2}}{2 \cdot c_{\mathrm{p}}} \\
c_{2}=\sqrt{2 \cdot c_{p} \cdot\left(T_{0 c}^{I N T}-T_{1 s}\right)} \\
c_{1 a}=c_{1} \cdot \cos \vartheta \cdot \cos (90-\varphi) \\
c_{1 u}=c_{1} \cdot \cos \vartheta \cdot \sin (90-\varphi) \\
c_{1 r}=c_{1} \cdot \sin \vartheta \\
w_{1 u}=c_{1 u}-u_{1}
\end{gathered}
$$

$$
\begin{aligned}
& w_{1}=\sqrt{c_{1 a}^{2}+c_{1 u}^{2}} \\
& \beta_{1 t}=\operatorname{acos} \cdot \frac{w_{1 u}}{w_{1}}
\end{aligned}
$$

Stationary blade efficiency is then:

$$
\eta^{R L}=\frac{T_{0 c}^{I N T}-T_{1 s}}{T_{0 c}^{I N T}-T_{1 i z}}=\frac{\frac{c_{1}^{2}}{2}}{H_{i z}^{R L}+\frac{c_{0}^{2}}{2}}
$$

\subsubsection{Traversing behind rotor}

From the evaluation point-of-view, this measurement is far more demanding, as it is necessary to first analyze the probe measuring behind stator to be able to define the inlet state in front of rotor. Additionally, it is necessary to make sure that measuring takes place at the utmost identical modes of the turbine operation.

Again, the analysed data are blade cascade losses and outlet angle (both in relative coordinate and absolute systems). Data is then averaged and plotted as radial dependences on the relative blade length.

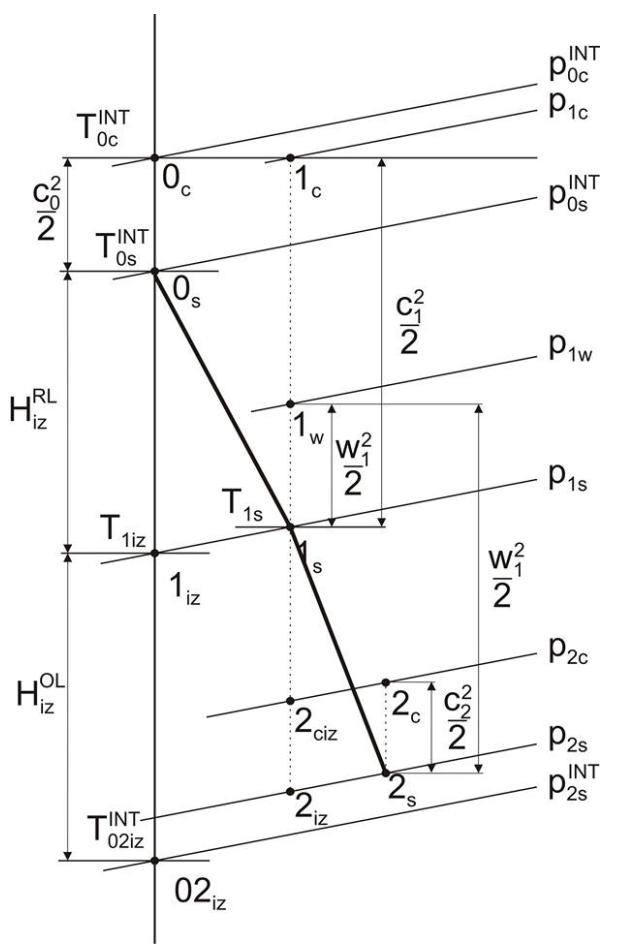

Figure 7. T-s diagram of stage expansion

As mentioned above, we need to know parameters of output state from stator to be able to determine the input state into rotor. Parameters $\rho^{S S}, \frac{c_{1}}{c_{02, i z}}, \frac{w_{1}}{c_{02, i z}}$ are used for integration and bonding of data behind stator and rotor. We obtain velocity $c_{02_{i z}}$ from the following relation:

$$
c_{02 i z}=\sqrt{2 \cdot H_{i z}^{S T}}
$$


We shall also need parameters $T_{02 i z}^{I N T}, H_{i z}^{S T}, T_{0 c}^{I N T}$, which were described in the chapter 4.2.1.

Isentropic drop on stationary blades can be written in the following form:

$$
H_{i z}^{R L}=\left(1-\rho^{S S}\right) \cdot H_{i z}^{S T}
$$

We will realize the calculation of parameters at the input into rotor on the basis of the following relations:

$$
\begin{gathered}
p_{1 s}=p_{0 s}^{I N T} \cdot\left(\frac{T_{1 i z}}{T_{0 s}^{I N T}}\right)^{\frac{\kappa}{\kappa-1}} \\
c_{1}=\left(\frac{c_{1}}{c_{02 i z}}\right) \cdot c_{02 i z} \\
w_{1}=\left(\frac{w_{1}}{c_{02 i z}}\right) \cdot c_{02 i z} \\
T_{1 s}=T_{0 c}^{I N T}-\frac{c_{1}^{2}}{2 \cdot c_{p}}
\end{gathered}
$$

We can consequently proceed to the calculation of expansion on rotor.

$$
\begin{gathered}
T_{1 w}=T_{1 s}+\frac{w_{1}^{2}}{2 \cdot c_{p}} \\
T_{2 i z}=T_{1 s} \cdot\left(\frac{p_{2 s}}{p_{1 s}}\right)^{\frac{\kappa-1}{\kappa}}
\end{gathered}
$$

We can estimate the velocity $c_{2}$ on the basis of the difference in isentropic temperatures:

$$
\tilde{c}_{2}=\sqrt{2 \cdot c_{p} \cdot\left(T_{2 c i z}-T_{2 i z}\right)}
$$

Where:

$$
T_{2 C i z}=T_{1 s} \cdot\left(\frac{p_{2 c}}{p_{1 s}}\right)^{\frac{\kappa-1}{\kappa}}
$$

Individual parts of the estimated absolute velocity are determined by the following relations:

$$
\begin{gathered}
\tilde{c}_{2}=\sqrt{2 \cdot c_{p} \cdot\left(T_{2 c i z}-T_{2 i z}\right)} \\
\tilde{c}_{2 a}=\tilde{c}_{2} \cdot \cos \vartheta \cdot \cos (90-\varphi) \\
\tilde{c}_{2 u}=\tilde{c}_{2} \cdot \cos \vartheta \cdot \sin (90-\varphi)
\end{gathered}
$$

Then the relative velocity from the estimated absolute velocity at the outlet from rotor is:

$$
\begin{gathered}
\widetilde{w}_{2 u}=\tilde{c}_{2 u}-u_{2} \\
\widetilde{w}_{2}=\sqrt{\tilde{c}_{2 a}^{2}+\widetilde{w}_{2 u}^{2}}
\end{gathered}
$$

Now we are able to define static and total temperatures at the outlet from rotor and calculate the real value of the outlet absolute velocity from rotor, including its components.

$$
\begin{gathered}
T_{2 s}=T_{1 w}-\frac{\widetilde{w}_{2}^{2}}{2 \cdot c_{p}} \\
T_{2 c}=T_{2 s} \cdot\left(\frac{p_{2 c}}{p_{2 s}}\right)^{\frac{\kappa-1}{\kappa}} \\
c_{2}=\sqrt{2 \cdot c_{p} \cdot\left(T_{2 c}-T_{2 s}\right)} \\
c_{2 a}=c_{2} \cdot \cos \vartheta \cdot \cos (90-\varphi) \\
c_{2 u}=c_{2} \cdot \cos \vartheta \cdot \sin (90-\varphi) \\
c_{2 r}=c_{2} \cdot \sin \vartheta
\end{gathered}
$$

Then the outlet relative velocity and the outlet flow angle from rotor are as follows:

$$
\begin{gathered}
w_{2}=\sqrt{c_{2 a}^{2}+w_{2 u}^{2}} \\
\beta_{2 f}=\operatorname{acos} \frac{w_{2 u}}{w_{2}}
\end{gathered}
$$

The final calculation is a determination of rotor efficiency, which we obtain from the following relation:

$$
\eta^{O L}=\frac{T_{1 w}-T_{2 s}}{T_{1 w}-T_{2 i z}}
$$

\section{Results of measured data}

It is necessary to mention at the beginning of this chapter that all the results from measuring on the experimental air turbine VT-400 belong to the property of DSPW, and therefore some courses of resultant parameters will be indicated in relative values.

The picture (Fig. 13) shows an efficiency comparison of both reaction blading tested variants of depending on the velocity ratio $\mathrm{u} / \mathrm{c}$. The efficiency value for variant "Pretlak-1"is slightly higher. The turbine optimum operating duty can be easily defined from both courses.

It is apparent from the Mach number behaviour on stationary blades (Fig. 8), that there is a deeply subsonic flow for both variants. Reynolds number ranges between 160000 to 180000 (Fig. 9) in the middle part of stationary blades. 


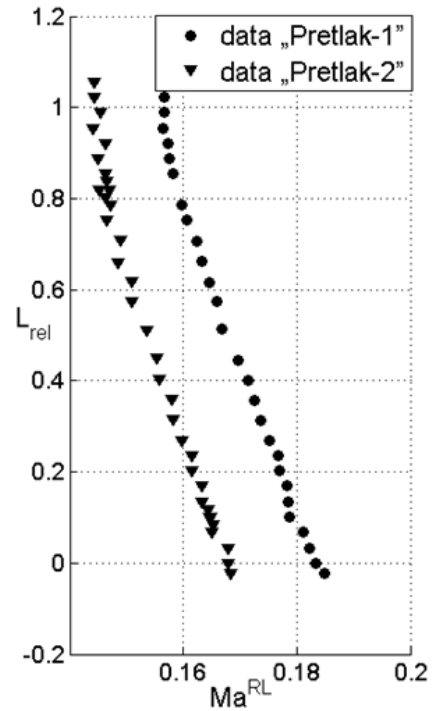

Figure 8. Mach number behaviour along a stator blade.

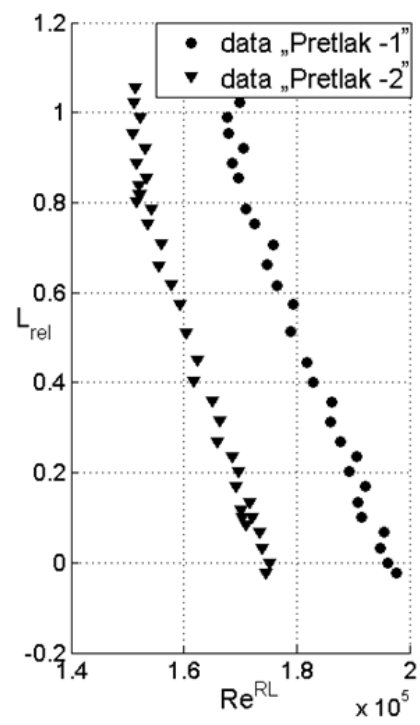

Figure 9. Reynolds number behaviour along a stator blade.

The following dependencies represent the reaction course (static-static) (Fig.10) and profile losses course separately on stationary and moving blades, depending on the blade relative length. (Fig. 11, Fig. 12). Distribution of profile losses along the stationary blades has an expected character. The losses value is low in the central part of the blade profile, but a significant losses increase occurs in the top of the blade, which we attribute to the influence of a space between the overshroud (tip) seal and the stator. This space is relatively high due to the axial gap between the stator and rotor and there may be a swirl flow, which partially extends also to the output flow from the stator blades. Profile losses along the moving blades are obviously higher in comparison with the stationary blades.

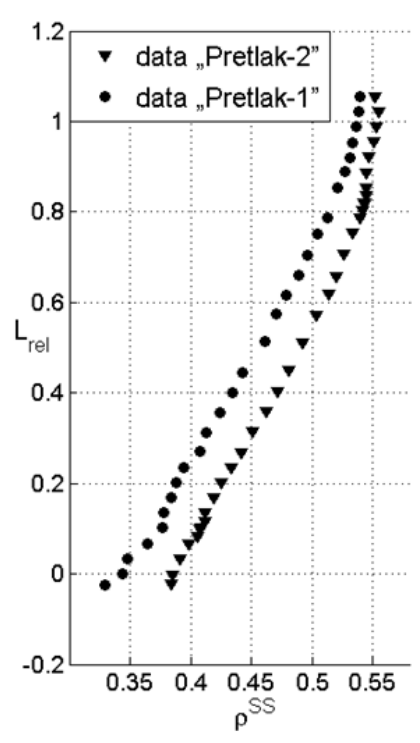

Figure 10. Reaction courses along the stator blade.

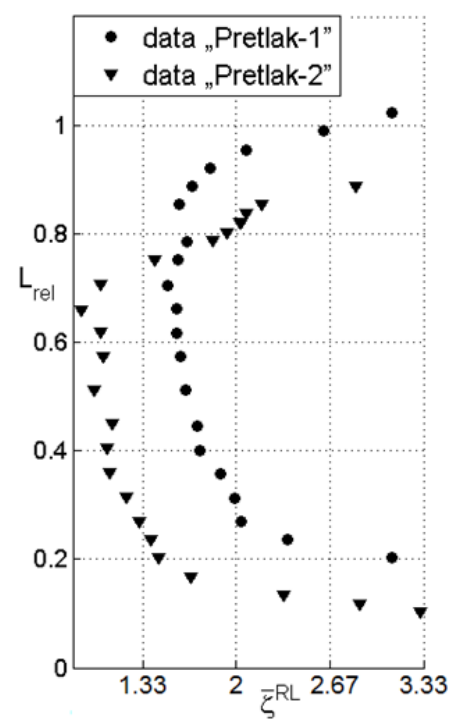

Figure 11. Profile losses courses along a stator blade.

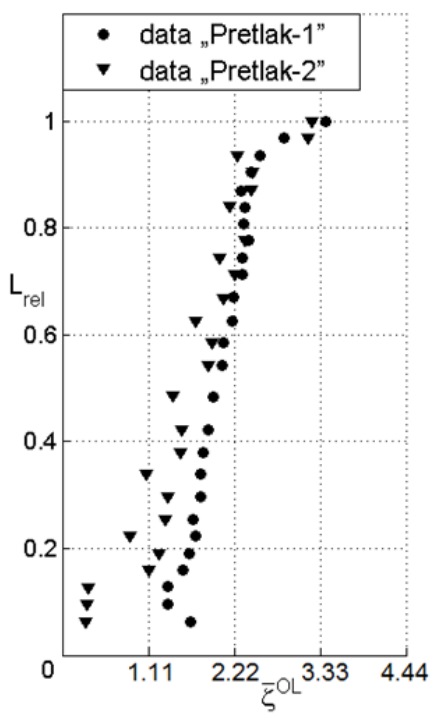

Figure 12. Profile losses courses along a rotor blade. 


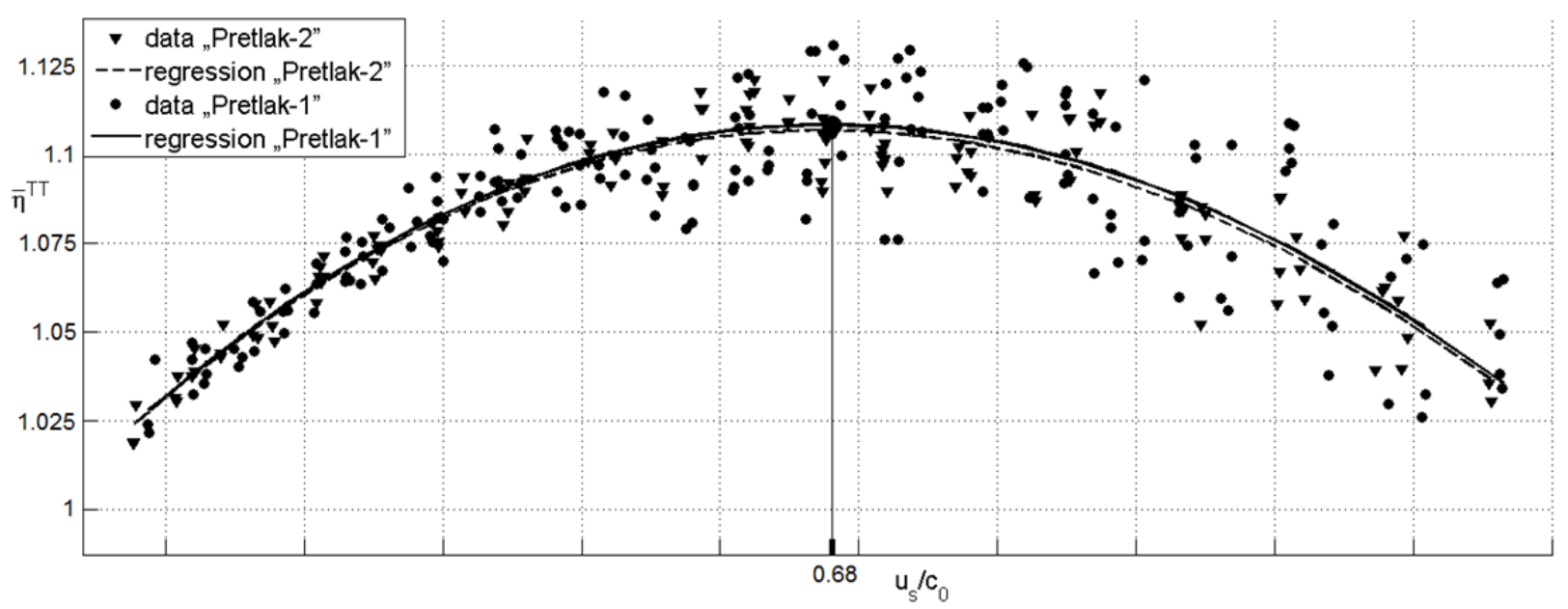

Figure 13. Efficiency comparison of tested variants.

Volume of profile losses is logically lower for stationary blades then for moving blades. As for the variants, the variant "Pretlak-2"demonstrates better results regarding losses in both cases, mainly due to better aspect ratio blade cascades. The middle part of the stationary bladefor the variant "Pretlak-1"displays far too high values of profile losses, which leads to the need of further testing.

\section{Conclusion}

At present, the experimental device is undergoing a fairly large reconstruction due to some outdated components. The compressor used up to now is sufficient as for its performance, yet its manual step regulation is inconvenient, likewise a possibility to maintain its constant operating duty.

Currently, pressure measurements are carried out by a 16-channel pressure transducer. To acquire more detailed information on stage integral parameters, the number of pressure measurements shall be doubled, and measurements will be extended by total states in front of and behind the stage using inserted probes.

As far as traversing behind stator and rotor is concerned, those measurements should carry on simultaneously after the reconstruction of the device, which shall simplify the evaluation process, and also reduce the measuring time.

Implementation of measuring system for nonstationary measurements by means of the measuring apparatus CTA (Constant Temperature Anemometry), which uses heated wire cooling for non-stationary measuring, is considered for the future, in addition to stationary measurements of tested stages.

\section{Acknowledgement}

The presented research is supported by the project CZ.1.05/2.1.00/03.0108 (Sustainable Energy, SUSEN) and student project SGS-2014-070 (Increasing the efficiency, reliability and durability of power system devices 3).

\section{References}

1. J. Vomela, Experimental and numerical development of turbine blades of high efficiency (5th European conference on turbomachinery, Praha, 2003)

2. J. Vomela, P. Milčák, The development of highefficiency turbine blades (Cieplne maszyny przeplywowe. Turbomachinery, Lodz, 2005)

3. P. Milčák, M. Hoznedl, D. Krivánka, Testování turbínového stupně s 3D lopatkováním - úvodní experiment (Mechanical Engineering Journal, 2009), ISSN 1335-2938

4. B. R. Haller, Full $3 D$ turbine blade design in secondary and tip clearance flows in axial turbines (von Karman Institute for Fluid Dynamics, 1997)

5. C. H. Sieverding, Recent Progress in the understanding of basic aspects of secondary flows in turbine blade passages (Journal of Engineering for Gas Turbines and Power, 1985).

6. P. Milčák, P. Žitek, M. Hoznedl, Comparison of Resultsfrom Experimental Testing of Three Variants of Turbine Stage with Modern 3D Blades (Experimental Fluid Mechanics, Liberec, 2012), DOI: 10.1051/epjconf/20134501063

7. P. Milčák, M. Hoznedl, P. Žitek, Measurement on stages with $3 D$ bladings and different relative width of stator blades (European Physics Journal, 2011), DOI: $10.1051 /$ epjconf/20122501054 